\title{
Zur Chemie des Nitroäthylens
}

\section{Doctoral Thesis}

\section{Author(s):}

Capaul, Marcel

Publication date:

1960

Permanent link:

https://doi.org/10.3929/ethz-a-000089331

Rights / license:

In Copyright - Non-Commercial Use Permitted 


\title{
Zur Chemie des Nitroäthylens
}

\author{
Von der \\ Eidgenössischen Technischen \\ Hochschule in Zürich \\ zur Erlangung \\ der Würde eines Doktors der technischen Wissenschaften \\ genehmigte \\ PROMOTIONSARBEIT
}

vorgelegt von

MAR C E L CAPA U L

dipl. Ing.-Chem. E. T. H.

von Lumbrein (Kt. Graubünden)

Referent: Herr Prof. Dr. H. Hopff

Korreferent: Herr Prof. Dr. V. Prelog

Juris·Verlag Zürich

1960 
1. Die Herstellung von Nitroäthylen wurde eingehend untersucht und die Verfahren und Ausbeuten wesentlich verbessert.

2. Als beste Laboratoriumsmethode erwies sich die thermische Spaltung des Nitroäthanolpropionats, gefolgt von einer Tieftemperaturfraktionierung, mit einer Gesamtausbeute von $43 \%$.

3. Die spärlichen Angaben der Literatur über die physikalisch-chemischen Eigenschaften des Nitroäthylens wurden in verschiedenen Richtungen ergänzt.

4. Die für die Stabilisierung des Nitroäthylens bestimmenden Faktoren waren Gegenstand mehrerer Versuchsreihen.

5. Die Anlagerung von Nitroäthylen an Verbindungen mit aktiven Wasserstoffatomen (Aminen, Amiden und Hydroxylverbindungen) wurde untersucht.

6. Es wurde ein Mechanismus der Nitroäthylierung vorgeschlagen und NitroäthylenNachweismöglichkeiten in Reaktionsgemischen studiert.

7. Durch Anlagerung von Nitroäthylen an N-Methylanilin und nachherige Reduktion wurde ein neuer Darstellungsweg mit guter Ausbeute für das N-Methyl-N-phenyläthylendiamin aufgezeigt.

8. Untersuchungen über die Isolierbarkeit nitroäthylierter aliphatischer und hydroaromatischer Amine wurde besondere Aufmerksamkeit geschenkt.

9. Durch Anlagerung von Nitroäthylen an Aminoanthrachinone wurden die entsprechenden $\mathrm{N}-(\boldsymbol{\beta}$-Nitroäthyl-) derivate hergestellt, die als Acetatseiden-Farbstoffe brauchbar sind. Vorstufen des Nitroäthylens reagierten mit Aminoanthrachinonen nicht.

10. Sämtliche Nitroäthylierungsversuche mit Aminen sauren Charakters, welche insbesonders die Beeinflussbarkeit der Reaktion mittels Katalysatoren und Druck abklären sollten, verliefen negativ.

11. Die Nitroäthylierbarkeit aliphatischer Alkohole wurde am Beispiel des n-Amyl-(2nitroäthyl)-äthers aufgezeigt; diejenige der aromatischen Reihe am 1-(2-Nitroäthoxy)anthrachinon. Dagegen waren unsubstituierte Phenole dieser Reaktion nicht zugänglich.

12. Zur Nitroäthylierung der Cellulose wurden mit Baumwolle und Zellwolle homogene und heterogene Umsetzungen vorgenommen, letztere nach verschiedener Vorbehandlung in Suspension und durch Bedampfen mit Nitroäthylendampf. Die Proben wurden mit Schwefelnatrium reduziert und auf Stickstoff analysiert. Die besten Resultate wurden durch Bedampfen nicht inkludierter Proben erhalten. Entsprechend dem Stickstoff Gehalt kam auf jeweils ca. 3 Glukoseeinheiten eine Aminoäthylgruppe (DS-Wert 1/3). Höhere DS-Werte liessen sich nicht erreichen, und bei teilweise veränderten physikalischen Eigenschaften blieb das Ziel, DS-Werte von 0,5 - 1,5 zu erreichen und eine wasserlösliche 2-Aminoäthylcellulose herzustellen, unerreicht. 